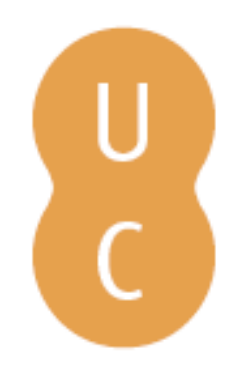

\title{
nommalina
}

\section{Projecto "e-Arquivos" estudo de caso do arquivo municipal de Ponte de Lima}

\author{
Autor(es): $\quad$ Freitas, Cristiana; Sousa, Paulo Jorge \\ Publicado por: Imprensa da Universidade de Coimbra \\ URL \\ persistente: URI:http://hdl.handle.net/10316.2/31886 \\ DOI: $\quad$ DOI:http://dx.doi.org/10.14195/978-989-26-0869-3_7 \\ Accessed : $\quad$ 26-Apr-2023 15:18:17
}

A navegação consulta e descarregamento dos títulos inseridos nas Bibliotecas Digitais UC Digitalis, UC Pombalina e UC Impactum, pressupõem a aceitação plena e sem reservas dos Termos e Condições de Uso destas Bibliotecas Digitais, disponíveis em https://digitalis.uc.pt/pt-pt/termos.

Conforme exposto nos referidos Termos e Condições de Uso, o descarregamento de títulos de acesso restrito requer uma licença válida de autorização devendo o utilizador aceder ao(s) documento(s) a partir de um endereço de IP da instituição detentora da supramencionada licença.

Ao utilizador é apenas permitido o descarregamento para uso pessoal, pelo que o emprego do(s) título(s) descarregado(s) para outro fim, designadamente comercial, carece de autorização do respetivo autor ou editor da obra.

Na medida em que todas as obras da UC Digitalis se encontram protegidas pelo Código do Direito de Autor e Direitos Conexos e demais legislação aplicável, toda a cópia, parcial ou total, deste documento, nos casos em que é legalmente admitida, deverá conter ou fazer-se acompanhar por este aviso.

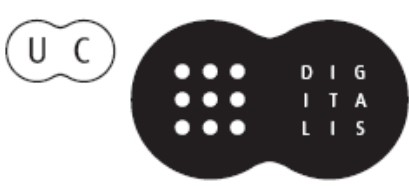


Maria Manuel Borges

Elias Sanz Casado

Coordenação

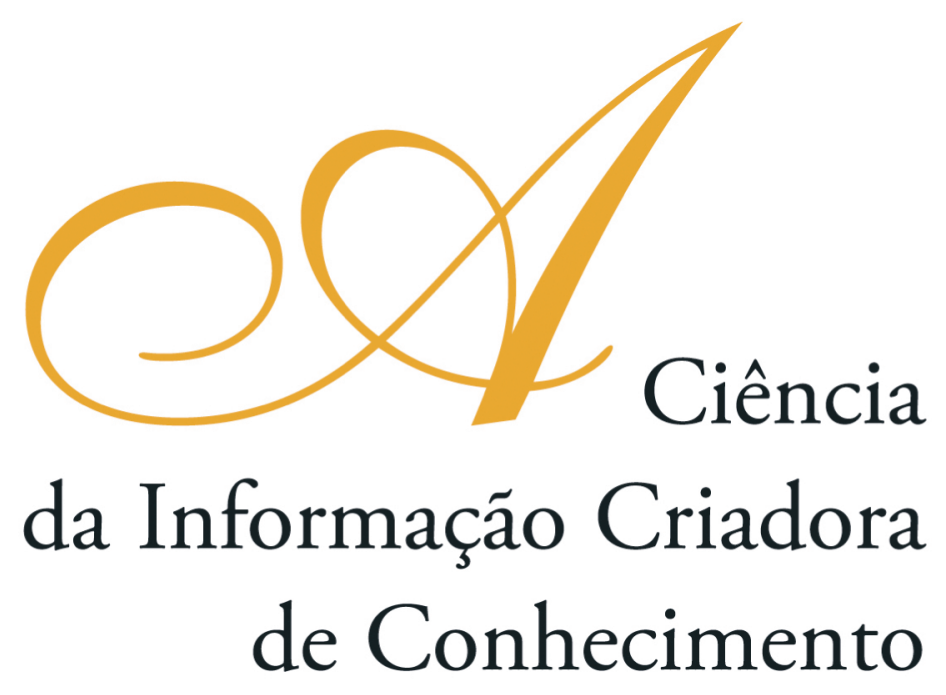

Vol. I I

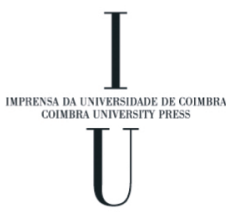

- COImbra 2009 
Projecto “e-Arquivos"

estudo de caso do Arquivo Municipal de Ponte de Lima

\section{Cristiana Freitas}

Arquivo Municipal de Ponte de Lima (Portugal)

Paulo Jorge Sousa

Câmara Municipal de Ponte de Lima (Portugal)

\section{Resumo}

Nesta comunicação apresentam-se algumas operações metodológicas e técnicas que o Município de Ponte de Lima assume no decurso da desmaterialização dos seus processos de informação analógica, que compõem o seu actual Sistema de Informação Municipal Activo e Permanente.

No actual contexto da sociedade da informação, tendo em atenção o papel central e fulcral da informaçáo como motor dinâmico do município na disponibilização de produtos e serviços de informação aos seus cidadãos, requer-se uma nova abordagem na produção, gestão, organização, representação, circulação e recuperação da informação, com a adopção dos meios tecnológicos necessários para as transformaçóes que dela decorre. Deste modo, o Sistema de Informaçáo Municipal Activo e Permanente enquadra-se num contexto orgânico-funcional dinâmico, que pode ser estudado e tratado com base numa perspectiva sistémica, à luz do novo paradigma - pós-custodial, informacional e científico - da ciência da informação.

O Arquivo Municipal de Ponte de Lima pretende-se afirmar como elemento vital na implementação da modernizaçáo administrativa, quer através do estudo do comportamento informacional dos utilizadores, quer através da optimização dos fluxos informacionais, melhorando, deste modo, a prestação de serviços multi-canal (digitais e analógicos), tanto para os utilizadores internos (serviços municipais), como para os utilizadores externos (munícipes).

A metodologia exposta nesta comunicação centra-se na apresentação de um caso de estudo, desenvolvido no âmbito do projecto "e-Arquivos", objecto de candidatura ao SAMA financiado pelo QREN, que compreende a desmaterialização dos Processos de Obras Particulares.

A desmaterialização destes processos pressupôe a identificação das tipologias documentais, do tipo de processos e dos fluxos de informação, com vista à simplificação e racionalização dos procedimentos existentes e ao reajustamento dos fluxos informacionais, decorrente do comportamento informacional dos vários agentes envolvidos. Estas decisóes implícitas ao tratamento da informaçáo terão grandes repercussóes no desenvolvimento de uma framework de serviços online a serem disponibilizados pelo município aos seus cidadáos.

\section{Abstract}

This communication sets out some methodological and technical operations that the Ponte de Lima county is taking over during the process of dematerialisation of their analogical information processes, that compose the current Municipal Active and Permanent Information System.

Within the scope of the information society and taking into consideration the central role of information as a dynamic motor for the municipality in providing products and information 
services to its citizens, it is necessary a new approach in the production, management, organization, representation, circulation and retrieval of information, by adopting the technologies needed for the transformation it creates. Thus, the Municipal Information System Active and Permanent positions itself on a dynamic organic-functional context, which can be studied and processed based on a systematic point of view, in light of the new paradigm - post-custodial, informational and scientific - of information science.

The Arquivo Municipal of Ponte de Lima intends to assert itself as an important element in the implementation of administrative modernisation, both by means of studying the user's informational behaviour and optimising informational flows, improving thus the rendering of multi-channel services (digital and analogical), both for internal users (municipal services) and for external users (residents).

The methodology described in this communication focuses on presenting a case study, developed under the project «e-archives» subject to the application Sama funded by NSRF, which includes the dematerialisation of Private Works Procedures.

The dematerialisation of these processes requires the identification of document types, of the type of processes and information flows, with a view to simplify and streamline existing procedures and adjust informational flows, arising from the informational behaviour of the several parts involved. These decisions, related with the processing of information, will have major repercussions on the development of a framework for online services to be provided by the county to its citizens.

\section{Introdução e objectivos}

A presente comunicação visa dar a conhecer o caso prático da desmaterialização dos Processos de Obras Particulares do Município de Ponte de Lima, desenvolvido no âmbito do projecto "e-Arquivos", objecto de candidatura ao SAMA (Sistemas de Apoios à Modernização Administrativa), bem como divulgar a metodologia utilizada no seu desenvolvimento, os caminhos já percorridos e os delineados para futuras acçôes.

Um dos factores críticos do sucesso da Modernização Administrativa é a desmaterializaçáo dos processos e a consequente reengenharia dos processos de trabalho assim como dos respeitantes fluxos de tarefas. Esta empreitada, visa o aumento da produtividade e a melhoria da qualidade dos serviços prestados ao cidadâo, emergindo-se como componente de capital importância, a curto prazo, os Processos de Obras Particulares.

Assim sendo, os objectivos gerais do projecto "e-Arquivos" são:

- Desmaterialização da informação dos processos de obras particulares;

- Implementação e reengenharia de processos;

- Criação de postos de atendimento para consulta digital dos processos em arquivo.

A desmaterialização destes processos e o planeamento, implementação e disponibilização de uma framework de serviços, quer físicos, quer digitais, deverão melhorar a relação e o processo de comunicação entre o município e os seus munícipes, além de contribuírem para um serviço público menos burocrático e mais eficiente, eficaz, célere e transparente. 


\section{Enquadramento do Sistema de Informação Municipal}

Com a mutação da tecnologia de acesso à Internet, entre outros, mashups, web semântica, serviços online, microformatos e a nova configuração da comunicação em massa, denominada por Manuel Castells (2006) como Mass Self Communication, veio-se elevar o nível da experiência de interacção e do comportamento informacional do utilizador, mormente o respectivo fenómeno info-comunicacional decorrente da interacção entre este e os sistemas tecnológicos de informação.

A Internet, é nos dias de hoje, o espaço de fluxo da sociedade da informação. Esta emergiu com o desenvolvimento terciário no pós-guerra, abrindo portas ao novo mundo digital onde a informação circula e transforma as economias digitais, altera os hábitos das pessoas, as relaçóes humanas, o trabalho e a produção/consumo de informação. A sociedade da informação, não é mais do que uma expressão que tenta sintetizar uma complexidade de factores que estáo "amarrados" às novas tecnologias e ao comportamento informacional dos utilizadores, os quais, por sua vez, estão "agrilhoadas" a um processo histórico global que nos remete para o final da II Guerra Mundial.

Neste contexto, o papel das autarquias locais, por estarem mais próximas do cidadão torna-se particularmente importante. Estas devem-se assumir com a determinação e convicção de que o futuro também depende da sua capacidade para se adaptar ao novo ritmo da Sociedade da Informaçáo e da Literacia Informacional. A concepção e a disponibilização de sistemas de informação e de sistemas tecnológicos de informação mais acessíveis e usáveis torna-se um factor estratégico de desenvolvimento com vista à melhoria da qualidade de vida das populaçóes.

No decorrer da modernização administrativa e organizacional, com o recurso às novas tecnologias de suporte à produção, gestão, recuperação, preservação e difusão da informação, a autarquia passa a estar muito mais próximo da sua comunidade, na medida em que os munícipes podem aceder aos serviços municipais de modo síncrono e assíncrono. Com a disponibilização do sistema integrado de informação do município advêm mais-valias como a diminuição do tempo de realização das tarefas associadas a cada processo; a rentabilização dos recursos humanos que lhe estão afectos, dotando-os, para tal, de ferramentas e métodos apropriados à prossecução das suas tarefas; o aumento da velocidade de acesso à informação; a melhoria da comunicação entre diversos serviços e destes com os seus munícipes; e, por último, contribui para a diminuição dos custos globais de funcionamento.

O Sistema de Informação (social) do Município de Ponte de Lima está em constante metamorfose, com fluxos informacionais cada vez mais activos, quer na sua estrutura orgânico-funcional, quer na sua relação com os diversos agentes externos (munícipes, parceiros públicos ou outros agentes privados). Esta mutação informacional evidencia-se particularmente no espaço de fluxo - a Internet - visando a necessidade crescente de disponibilizar os novos recursos digitais, produzidos e adquiridos, quer pelos diversos serviços e unidades orgânicas, quer pelos agentes externos supracitados.

Por sua vez, o Município de Ponte de Lima tem vindo a desenvolver e a disponibilizar novos sistemas tecnológicos de informação que suportem o seu conhecimento explícito (informação social) de uma forma integrada, atendendo às constantes necessidades dos seus utilizadores e da própria evolução tecnológica. 
Face a este comportamento, o Arquivo Municipal de Ponte de Lima ao liderar o projecto "e-Arquivos" pretende afirmar-se como elemento vital na implementação da modernização administrativa. Essa importância é sustentada pelo facto do arquivo melhorar o sistema de informação do município assim como optimiza os fluxos informacionais, melhorando, desta forma, a prestação de serviços multi-canal (digitais e analógicos), tanto para os utilizadores internos (serviços municipais), como para os utilizadores externos (munícipes).

Circunscrita deste modo, a informação (social) assume-me como o núcleo, o epicentro de toda a reengenharia organizacional e informacional. Actualmente, existe uma grande multiplicidade de abordagens e tentativas de precisar com mais rigor a definição de informação. Como tal, retemo-nos naquela que tenta congregar de uma forma mais abrangente e concisa este conceito, que pode ser descrito como um "conjunto estruturado de representaçóes mentais e emocionais codificadas (signos e simbolos) e modeladas com/pela interacção social, passiveis de serem registadas num qualquer suporte material (papel, filme, banda magnética, disco compacto, etc.) e, portanto, comunicadas de forma assincrona e multi-direccionada" (Silva, 2006). Definida deste modo, a 'informação' constitui-se como o objecto científico da Ciência da Informação.

Epistemologicamente sustentada, esta ciência assenta numa estrutura teóricometodológica própria e sólida no seio do "paradigma emergente pós-custodial, informacional e cientifico, pelo contributo e simbiose da Arquivistica, da Biblioteconomial Documentação, dos Sistemas de Informação e da Museologia (renovada e não patrimonialista)" (Silva, 2006). Os campos de estudo e de actuação da Ciência da Informação centram-se em três áreas que se inter-relacionam activamente, mormente: o Comportamento Informacional, a Gestão da Informação e a Organização e Representação da Informação. Sobre "cada uma delas ou nas suas diversas intersecçóes desenvolvem-se os ramos aplicacionais quer envolvendo os constructos convencionais (Arquivo, Biblioteca, Centro de Documentação), quer a implementação e desenvolvimento de sistemas informáticos (sistemas tecnológicos de informação) na óptica dos utilizadores/ clientes em contextos orgânicos, subsumidos na teoria sistémica pelo conceito operatório de Sistema de Informação" (Silva, 2006).

O presente caso de estudo - projecto "e-Arquivos" - emerge, sob a perspectiva da Ciência da Informaçáo, a partir do ramo aplicacional do Arquivo - enquanto serviço -, exigindo uma participação mais saliente da Gestão da Informação e da Organização e Representação da Informação.

Posto isto, cabe-nos dar a conhecer o papel que o Arquivo Municipal de Ponte de Lima tem desempenhado no que se refere à dualidade conservação versus difusão e ao aproveito das Tecnologias da Informação e Comunicação (TIC).

Ao Arquivo Municipal de Ponte de Lima, instalado em edifício próprio no centro histórico da vila, desde 2004, é-lhe incumbido, entre outras funçôes, a gestão integrada da informação de natureza 'arquivística' dos diferentes órgáos e serviços do município.

Sendo este, seguramente, um dos mais ricos arquivos locais do país, foi submetida, em 2005, uma candidatura à medida 2.2, acçáo 3 - "Tratamento e digitalizaçáo de documentos do Arquivo Municipal de Ponte de Lima”, do Programa Operacional de Cultura (POC). Esta candidatura, teve como objectivo a promoção e divulgação do património arquivístico, salvaguardando e conservando os documentos originais. 
Para tal, tornou-se imprescindível o recurso às novas tecnologias e, por conseguinte, à transferência de suporte.

No âmbito deste projecto foi digitalizada uma parte significativa do espólio documental - 1.491 documentos - que constituí o vulgarmente denominado arquivo histórico, num total de 188.676 imagens.

O projecto, pioneiro a nível distrital na disponibilização online de documentos em suporte digital, permitiu ainda, entre outras acçôes, criar o website do Arquivo Municipal onde, para além de outras informaçôes pertinentes, é possível o acesso online ao Catálogo Documental, com a ligação dos registos ao texto integral (imagens digitalizadas). Este website constitui assim, um importante serviço enquanto fonte de informaçáo, quer para os serviços internos, quer para os demais perfis de utilizadores externos. Aceda ao website no endereço: http://www.arquivo.cm-pontedelima.pt.

Actualmente, no que se refere à documentação administrativa o acesso à informação nela contida é efectuado exclusivamente sob a forma presencial. Assim sendo, quando um munícipe pretende consultar um Processo de Obras Particulares tem de dirigir-se à Secção de Obras da Câmara Municipal ou ao edifício do Arquivo Municipal. O mesmo acontece com a requisiçáo de Processos de Obras Particulares, por parte da Secção de Obras, o que implica, necessariamente, a deslocação de um funcionário ao Arquivo Municipal.

Com o projecto "e-Arquivos" o Arquivo Municipal de Ponte de Lima pretende contribuir activamente para a introdução de uma nova dinâmica na modernização administrativa ao nível dos serviços - objectivando a desburocratização e a reengenharia de processos, o aumento da eficácia, eficiência, celeridade e transparência e, ainda, a redução de custos - bem como ao nível da interacção/comunicação entre o município e os munícipes.

No entanto, apesar dos diversos edifícios municipais estarem ligados por fibra óptica, actualmente, não há integração entre o sistema utilizado pelo arquivo - ArqHist, da empresa SHP - e os restantes sistemas tecnológicos de informação existentes no município.

Nesta conformidade, torna-se necessária a implementação de uma Gestão Integrada do Sistema de Arquivo do Município de Ponte de Lima. Esta deverá permitir agregar o Portal de Atendimento (sistema de gestão documental - desenvolvido no âmbito do projecto Valimar Digital) com a componente de gestão de arquivo numa solução única e integrada, minorando os riscos de falha de comunicação entre as aplicaçóes de software e a perda de metadados e de objectos digitais ao longo do tempo.

A integração do Portal de Atendimento com o Sistema de Arquivo é um processo crítico para o Município de Ponte de Lima, quer ao nível da sua interoperabilidade, quer ao facto da gestão da informação da instituição se constituir como uma componente nuclear no desenvolvimento da mesma.

\section{O projecto "e-Arquivos"}

Este projecto, induzido no novo paradigma pós-custodial, informacional e científico, visa a reengenharia e modernização do Sistema de Informação do Município de Ponte de Lima. Na tentativa de acautelar eventuais confusôes, convém referir que o conceito 
operatório de 'Sistema de Informação' em Ciência da Informação se distingue do Sistema Tecnológico de Informação.

Este sistema é constituído pelos "diferentes tipos de informaçâo registada ou não externamente ao sujeito (o que cada pessoa possui em sua memória é informação do sistema), não importa qual o suporte (material e tecnológico), de acordo com uma estrutura (entidade produtoralreceptora) prolongada pela acção na linha do tempo" (Silva, 2006).

Apesar do Arquivo Municipal ter um papel muito relevante enquanto receptor de informação, este apenas se constitui como um elemento (micro) à semelhança de outros, como os Serviços Jurídicos, que também produzem e recebem informação. Recorrendo à teoria sistémica, pode definir-se operatoriamente o Sistema de Informação do Município de Ponte de Lima como "um complexo unitário formado por uma pluralidade de elementos relacionados entre si e de tal forma que: (a) apresente características próprias; (b) o estado de cada elemento dependa pelo menos de um outro $e$ acabe condicionado pela estrutura toda; (c) esta, se assumir ou modificar o próprio "estado", afecta os seus elementos, assumindo cada um deles um dado estado ou sofrendo uma modificação de estado; $e$ (d) todos os elementos são necessários para formar aquela estrutura (MELLA, 1997: 25). Infere-se, assim, que toda a estrutura é, simultaneamente, estruturada (o seu estado deriva dos elementos integrantes) e estruturante (o seu estado condiciona o dos elementos)" (Silva, 2006).

Pode-se classificar o Sistema de Informação de Ponte de Lima como um sistema (semi)fechado de informação social, escorados por dois factores essenciais - a natureza orgânica (estrutura) e a natureza funcional (serviço/uso) - aos quais se imbrica a memória. À medida que a sua estrutura orgânico-funcional vai evoluindo e adaptando às constantes mutaçóes ambientais, também o seu Sistema de Informação vai crescendo por força do fenómeno info-comunicacional. A sua estrutura orgânico-funcional estimula a "acção do fenómeno info-comunicacional através da sua função, ou seja, através da sua actividade no cumprimento da sua missão e objectivos. Só depois desse feedback dentro do contexto é que se desenvolve o fenómeno info-comunicacional e o uso da informação" (Silva, 2002, p. 254).

$\mathrm{Na}$ sequência do projecto Valimar Digital foi recentemente apresentada uma nova Candidatura pela Comunidade Urbana, no âmbito do SAMA (Sistemas de Apoio à Modernização Administrativa), que mereceu igualmente a aprovação do QREN, designado por "e-Arquivos" e que compreende a desmaterialização dos Processos de Obras Particulares.

Considerando que os Processos de Obras Particulares à guarda do Arquivo Municipal constituem o tipo de documentaçáo mais solicitada, quer pelos utilizadores internos (serviços municipais), quer pelos utilizadores externos (munícipes), optou-se por proceder à sua desmaterialização, tendo como objectivos:

- Racionalizar, simplificar e desmaterializar os processos de gestão urbanística;

- Reestruturar o contexto organizacional;

- Modernizar e agilizar a gestáo documental;

- Aumentar a facilidade e rapidez da difusão documental e da sua acessibilidade via Web, contemplando os cidadáos com necessidades especiais;

- Melhorar o atendimento presencial;

- Diminuir os "custos públicos de contexto";

- Preservar os documentos. 
Para além da desmaterialização dos Processos de Obras Particulares, o projecto contempla:

- A aquisição e instalação de scanners A2 e A0 no Arquivo Municipal;

- A aquisiçáo de PC's para a criação de postos de consulta;

- A aquisição de uma solução de software para a gestão dos processos de obras em arquivo e a integração da informação com os restantes sistemas tecnológicos de informação existentes no município, através de web services.

\section{Antecedentes}

Têm surgido, na última década, programas promotores da cidadania digital - e-local government - aos quais se têm candidatado inúmeros municípios.

Foi neste âmbito que surgiu recentemente o projecto Valimar Digital, que consiste num "dos mais ambiciosos projectos da Comunidade Urbana Valimar (Valimar ComUrb), quer pela sua importância a nivel regional, quer pelos objectivos que norteiam a sua realização. Ao candidatar o Valimar Digital ao Programa Operacional da Sociedade do Conhecimento - Medida Cidades e Regióes Digitais, a Comunidade Urbana [composta pelos Municipios de Arcos de Valdevez, Caminha, Esposende, Ponte da Barca, Ponte de Lima e Viana do Castelo] encetou um novo rumo e alargou-se a novos desafios. $O$ aumento da competitividade da região, através da disseminação da Sociedade da Informação e do Conhecimento, afigura-se como uma das premissas da Valimar ComUrb para um futuro próximo". 1

Em suma, o projecto permitiu:

- O desenvolvimento da plataforma da Valimar com o intuito de facilitar a comunicação e interacção entre a população, os municípios e as comunidades portuguesas;

- Promover a utilização de tecnologias de informação e comunicação através da disponibilização de ferramentas e serviços de forma a permitir a participação dos cidadãos na vida pública local, factor fundamental para um sustentado desenvolvimento regional;

- Reformular os websites dos municípios, de forma a melhorar a qualidade dos serviços prestados ao cidadão, facilitar a comunicação com o munícipe e reforçar a participação democrática;

- Implementar novos canais de interacção com o munícipe através da disponibilização de serviços úteis na Internet - submissão de requerimentos e outros documentos; consulta remota do estado de processos; pagamento de taxas e licenças; envio de notificaçóes e recepção de alertas multi-canal e disponibilização de instrumentos geo-referenciados de apoio aos processos de obras;

- Implementar um modelo de trabalho homogéneo para todos os funcionários municipais, bem como um novo modelo de atendimento ao público, com o recurso às novas tecnologias da informação e comunicação, assente na disponibilização de novos

\footnotetext{
${ }^{1}$ In: http://www.valimardigital.pt/portal/page/portal/visitantes/val_dig
} 
meios de relacionamento município-munícipes e na modernização do funcionamento interno dos municípios da região;

- Interligar os diversos edifícios camarários através de uma rede de fibra óptica, de forma a melhorar os fluxos de informação entre parceiros.

Os municípios do Vale do Lima passaram a disponibilizar através dos respectivos websites/portais conteúdos e serviços online, introduzindo assim uma nova dinâmica de modernização administrativa ao nível dos serviços - redução da burocracia e reengenharia de processos; aumento da eficácia, eficiência, transparência e a redução de custos - bem como ao nível do relacionamento entre município-munícipes, que se pretende mais próximo. Pretende-se que os portais municipais sejam o canal preferencial de comunicação com os munícipes, funcionando como balcôes de atendimento.

Nesta lógica, para além da informação de caris generalista, relativa à história, cultura, gastronomia e geografia do município, é permitido o acesso a todo o tipo de documentos em uso nas respectivas autarquias tais como regulamentos, requerimentos/ formulários "relativos aos serviços para download, que permite ao cidadão aceder à documentaçâo necessária e aos respectivos impressos, em formato electrónico, que lhe permitem posteriormente, em modo presencial, requerer um dado serviço. É uma pequena melhoria, que permite evitar algumas idas aos serviços para tratar um determinado assunto ou para requer um dado serviço". (Santos \& Amaral, 2003, p. 15).

\section{Planeamento estratégico}

O enfoque da actuação do projecto "e-Arquivos" foi delimitado às áreas associadas à informação, nomeadamente aos modos da sua aquisição, circulação, gestão, armazenamento e recuperação. Com o planeamento estratégico deste projecto pretendeuse compreender melhor a ecologia informacional, qual o ciclo de vida da informação dentro do sistema global de informação do Município, quais os agentes que produzem e adquirem a informação. Neste contexto, o serviço de Arquivo passou a ter um papel muito mais activo e interventivo na dinâmica organizacional.

Desde modo, e partindo do princípio que "o conceito autarquia digital náo remete de imediato para a Web. Pressupóe, antes, um aturado trabalho no interior das Câmaras Municipais, departamento a departamento, divisão a divisão, serviço a serviço, preparando o back-office para a sua ligação para a rede. Formados os quadros, redesenhados os procedimentos, feita a incorporaçáo tecnológica, (re)estruturada a missão, (re)definidos os objectivos, optimizada a comunicação interna, é, então, chegada a altura de se avançar para o front-office e conceber a arquitectura do lugar que se vai ocupar no ciberespaço" (Ribeiro, 2005, p. 114) foram tidas em conta as seguintes acçôes:

- estudo das funçôes e competências do serviço; ${ }^{2}$

2 Pese embora este estudo de caso centre a sua actividade nos Processos de Obras Particulares, na verdade este estudo que pretende tornar intangível a função serviço/uso estende-se a todos os serviços municipais. Porém, sabe-se que "na prática, nem sempre se aplicam todas as determinaçôes previstas pela lei. Por razôes de diversa ordem, há reformas que não se concretizam, no todo ou em parte, há acções que não se regulamentam nunca e há outras que só a posteriori são enquadradas por uma disposição legal e, por vezes, apenas parcelarmente”. (Ribeiro \& Fernandes, 2002, p. 47) 
- identificação das tipologias documentais e dos tipos de processos;

- análise dos fluxos de informação, com vista à reengenharia dos processos.

Estes estudos preliminares tiveram como principais objectivos "detectar anomalias do sistema, nomeadamente deficiência nos seus circuitos e ausência de controlo em diversos momentos (na recepção, na tramitação e, mesmo, na expedição), funcionando, pois, como instrumento correctivo e de optimizaçâo, em termos prospectivos, com vista a uma maior eficácia da função serviçoluso (...) Salienta-se, portanto que por acção do Arquivo se questionam procedimentos, se analisam e se repensam circuitos informacionais e se implementam medidas tendentes a tornar mais eficaz a transmissibilidade e a recuperação da informação, com a finalidade clara de contribuir para uma melhor gestão organizacional". (Ribeiro \& Fernandes, 2002, p. 48)

Posto isto, no âmbito deste projecto, irá proceder-se às seguintes acçóes:

- Digitalização dos Processos de Obras Particulares no Arquivo Municipal com recurso a equipamento especializado conforme a tipologia documental - scanner de rolo A0 para plantas, projectos, telas finais e scanner A2 para a restante documentação.

Pretende-se a captura de imagens em três formatos diferentes:

- Thumbnails - imagem de baixa resoluçáo e de dimensões reduzidas com 72 dpi's (entre 5 e $100 \mathrm{~Kb}$ ) para visualização;

- Ficheiro Jpeg - imagem de média resolução com, no mínimo, 200 dpi’s para impressão e visualização, na sala de leitura, em écran de 17";

- Matriz digital em formato Tiff - imagem de alta resolução e sem compressão, com, no mínimo, 300 dpi's, sem tratamento de imagem. Esta matriz digital destina-se à conservação do documento.

- Organização e tratamento dos processos digitais, bem como a criação de índices, utilizando-se para tal a designação das tipologias documentais que os constituem. Os objectos digitais são associados à respectiva descrição documental e disponibilizados para consulta/reprodução;

- Assentando numa perspectiva sistémica para a Gestão Integrada do Sistema de Informação Municipal Activo e Permanente, deverá ser desenvolvida uma aplicação que garanta o cumprimento de todos os requisitos e normas necessárias, agregando o Portal de Atendimento com a componente de gestão de arquivo numa solução única e integrada, permitindo a gestão das diversas fases do ciclo de vida da informação. Pretende-se, ainda, que o sistema esteja preparado para abordar qualquer arquivo, independentemente do ciclo de vida da informaçáo, do formato ou da técnica de registo e que respeite escrupulosamente as normas, protocolos e boas práticas, tais como ISO 15489, EAD 2, MOREQ 2, OAIS Model, ISO 14721:2003, MIP, NP 4438:1-2, ISAD (G) 2, ISAAR (CPF) 2, ISDIAH, ISDF, ODA I, II e III, EAC 2, Z39.87 (MIX) e OAI/PMH;

- Criação de web services para a integração deste sistema com outras aplicações existentes no Município de Ponte de Lima, designadamente na Secção de Obras Particulares, na qual é utilizada uma aplicação da empresa Medidata para a gestão de obras;

- Disponibilização da informação através do website do Município. Assim, para além do acesso à informação no posto de atendimento existente na Sala de Leitura do Arquivo Municipal, os munícipes poderão ainda proceder à consulta online da informação; 
- Implementação de medidas de análise de requisitos, planeamento, concretização e avaliação dos modelos, normas e soluçóes tecnológicas adequadas para a preservação dos recursos digitais, evitando-se, assim, a perda irremediável de informaçáo pertinente à constituição e consolidação da memória colectiva do concelho de Ponte de Lima;

- Implementação de um repositório digital que deverá assumir-se como um recurso crítico dentro da carteira de aplicações do Município. Além de permitir o depósito, gestáo e acesso aos objectos digitais entretanto criados, deverá passar a assumir relevância crescente na adopção de estratégias para a criação de valor acrescentado no Sistema de Informação com base no desenvolvimento de uma framework de serviços integrados de informação devidamente alicerçados no acesso e uso da informação contida no repositório digital. Esta mais valia poderá constituir-se como um recurso de informaçáo de inegável valor, quer no acesso corrente, quer para a salvaguarda do património informacional, cultural e etnográfico do concelho de Ponte de Lima.

Dada a dinâmica e a complexidade do sistema de informação do município, a nossa estratégia também visa a mudança da cultura organizacional, disponibilizando pequenas sessôes de formação e orientação presencial, quer para o acesso e uso do Sistema de Informação Municipal Activo e Permanente, quer na melhoria da gestão da informação de acordo com boas práticas entretanto definidas. $\mathrm{O}$ modo como cada funcionário/colaborador do município gere a informação no seu local de trabalho é fundamental para a melhoria do sistema de informação, tendo em conta que este já se encontra moldado de acordo com a estrutura orgânica e a função serviço/uso.

\section{Objectivos concretizados}

Conforme referido anteriormente, o projecto "e-Arquivos" pressupôs uma análise profunda do sistema de informação, com vista à sua optimização, tornando a informação mais acessível e usável pelos serviços que a produz e/ou recebe, em todas as fases do seu ciclo de vida.

Neste âmbito, foram concretizadas as seguintes acçôes:

- Com vista à elaboração do plano de classificação, procedeu-se à identificação, junto da Secção de Obras Particulares, de toda a informação produzida e a sua contextualização na função/competência que esteve na sua origem;

- Procedeu-se ao levantamento das tipologias documentais, a partir do qual se pretende implementar a normalização das designaçóes;

- Identificação dos tipos de processos e análise/desenho dos respectivos workflows, com vista à optimização do seu funcionamento;

- Avaliação das necessidades do serviço relativamente à desmaterialização dos Processos de Obras Particulares - o que digitalizar, por onde começar.

Deve referir-se que este estudo, não se restringiu apenas à Secção de Obras Particulares, foi extensível aos restantes serviços municipais.

Este projecto, para o qual contribuíram grande parte dos funcionários do Município, permitiu desenvolver nestes a "consciencializaçâo de que gerir adequadamente a informação é um requisito com carácter de obrigatoriedade e que, muito mais que um mero apoio à gestão institucional corrente, constitui um recurso fundamental para delinear uma visáo estratégica e prospectiva da instituiçâo" (Ribeiro \& Fernandes, p. 22). 


\section{Trabalho futuro}

Visando a gestão integrada do Sistema de Informação Municipal Activo e Permanente torna-se imprescindível conhecer toda a produçáo documental e os respectivos fluxos da informação. Assim, após a realização destas operaçôes, vamo-nos concentrar nas próximas acçóes imediatas, nomeadamente:

- Integração do Portal de Atendimento com as restantes aplicações informáticas em uso no Município;

- Acompanhamento do progresso da nova solução que irá permitir gerir as várias fases do ciclo de vida da informação no município (Portal de Atendimento mais a componente de gestão integrada de arquivo) - já se encontra em desenvolvimento pela empresa que disponibilizou o Portal de Atendimento;

- Digitalização dos Processos de Obras Particulares no Arquivo Municipal;

- Disponibilizaçáo do repositório digital, quer para a gestáo/depósito de todos os objectos multimédia produzidos pelos vários serviços do Município, quer para o eventual suporte ao armazenamento dos objectos digitais provenientes da soluçáo totalizada (Portal de Atendimento mais a componente de gestão integrada de arquivo);

- Preparar e disponibilizar pequenas sessôes de formação e de orientação presencial, quer para o acesso e uso do Sistema de Informação Municipal Activo e Permanente, quer de melhoria da gestão da informação de acordo com boas práticas entretanto definidas.

A médio prazo, pretende-se executar as seguintes tarefas:

- Lançar as bases para a implementação de um sistema de avaliação da informação, já que esta é uma operação essencial ao desenvolvimento do Sistema de Gestão Integrada da Informação Municipal;

- Visando uma perspectiva mais holística no design do sistema de serviços do Município de Ponte de Lima, deverá ser desenvolvida uma framework com o design do sistema de serviços a disponibilizar, recorrendo, por exemplo, ao método multidisciplinar Service Experience Blueprint (Patrício, Fisk, \& Cunha, 2008), o qual envolve a aplicação de métodos de Design de Serviços e de Design da Interacção. Deste modo, todos os serviços a ser disponibilizados, quer via canal físico, quer canal digital, são estudados e analisados visando a sua optimização e gestão de acordo com a experiência de interacção dos munícipes.

\section{Conclusão}

Um dos factores críticos de sucesso da Modernização Administrativa Local é a desmaterialização dos processos e a consequente reengenharia dos processos organizacionais, visando o aumento da produtividade e a melhoria da qualidade dos serviços prestados ao cidadáo.

É nesta medida que se insere o projecto "e-Arquivos" que visa a desmaterialização dos Processos de Obras Particulares à guarda do Arquivo Municipal de Ponte de Lima. Trata-se da documentação mais solicitada, quer pelos utilizadores internos (serviços municipais), quer pelos utilizadores externos (munícipes), sendo consequentemente a que implica maior esforço de consulta e a que está mais susceptível, quer à degradação 
física causada pelo constante manuseamento, quer à possibilidade de extravio de documentos e/ou dos processos.

Da desmaterialização de processos aliada à disponibilização do Sistema Integrado de Informação do Município advêm mais-valias, tais como:

- Diminuiçáo do tempo de realizaçáo das tarefas associadas a cada processo;

- Rentabilização dos recursos humanos que lhe estáo afectos, dotando-os de ferramentas e métodos apropriados à prossecução das suas tarefas;

- Aumento da rapidez de acesso à informação;

- Melhoria da comunicação entre diversos serviços e destes com os seus munícipes;

- Diminuição dos custos de funcionamento globais.

Parte dos objectivos do projecto "e-Arquivos" já se encontram concluídos, contudo os que se encontram em desenvolvimento afiguram-se como cruciais para o sucesso global do mesmo, nomeadamente a disponibilização do Sistema Integrado de Informação do Município que irá permitir gerir as várias fases do ciclo de vida da informação (Portal de Atendimento mais a componente de gestão integrada de arquivo) e a respectiva integração desta solução com as restantes aplicaçôes informáticas em uso no Município.

Neste estudo de caso sintetizamos o trabalho efectuado à luz do novo paradigma - pós-custodial, informacional e científico - da ciência da informação, o qual se constitui como um pequeno contributo para a consolidação e expansão do seu corpus epistemológico. Através deste estudo é possível extrair elementos observáveis noutros sistemas de informação municipais, tendo por base o cruzamento das mesmas operaçóes metodológicas e técnicas.

\section{Referências bibliográficas}

Castells, Manuel (2006) - Emergence des «médias de masse individuels» Le Monde Diplomatique. Em linha http://www.monde-diplomatique.fr/2006/08/CASTELLS/13744

Patrício, Lia; Fisk, Raymond, Cunha, João Falcão e (2008). Designing multi interface service experiences: the Service Experience Blueprint. Journal of Service Research, Vol.10 n. ${ }^{\circ}$, pp.318-334.

Presença das câmaras municipais portuguesas na internet em 2002. Lisboa: Gávea. Em linha http://repositorium.sdum.uminho.pt/bitstream/1822/300/1/ArtCadEcon2002.pdf

Ribeiro, F., \& Fernandes, M. E. M. (2001). Universidade do Porto: Estudo orgânico-funcional (Modelo de análise para fundamentar o conhecimento do Sistema de Informaçáo Arquivo). Porto: Reitoria da Universidade.

Ribeiro, N. (2005). Municipios on-line: a rede como suporte a novas práticas de governação local. Em linha http://www2.ufp.pt/ lmbg/monografias/msc_nicolau06.pdf

Rodotà, S. (1999). Para uma cidadania electrónica: a democracia e as novas tecnologias da comunicação, Colecção Debates Presidência da República. Lisboa: INCM, 121-150.

Santos, S., Mendes, S. M. \& Amaral, L. (s.d.). E-government e outras politicas para o fomento de participação pública. Em linha http://bath.eprints.org/5316/1/Tese\%20__tima.pdf

Silva, A. M. (2006). A Informação: da compreensão do fenómeno e construção do objecto científico. Porto: Ediçóes Afrontamento.

Silva, A. M., et al. (2002). Arquivistica: Teoria e prática de uma ciência da informação. 2a ed. Porto: Ediçōes Afrontamento. 